\title{
Structural Characterization of Cu10Mo Alloy Synthesized by Mechanical Alloying
}

\author{
O. Hernández ${ }^{1}$, C. Aguilar ${ }^{2}$, A. Medina ${ }^{1}$, L. Béjar ${ }^{1}$, C. Parra ${ }^{3}$, H. Carreón ${ }^{1}$, S.E. Borjas-García ${ }^{1}$
}

1.UMSNH. Ciudad Universitaria. Morelia, Michoacán. México 58000

2. Departamento de Ingeniería Metalúrgica y Materiales, Universidad Técnica Federico Santa María, Av. España 1680, Valparaíso, Chile

${ }^{3}$ Departamento de Física, Universidad Técnica Federico Santa María, Av. España 1680, Valparaíso, Chile.

Copper and its alloys have good electrical and thermal conductivity as well as good resistance to corrosion [1] but it has a low mechanical strength. However, its mechanical strength can be improved by adding alloying elements by means of Mechanical Alloying (MA) and powder metallurgy [2-5].

In this work we report the results of the Cu10Mo alloy, synthesized during $10 \mathrm{~h}$ by MA. The microstructural characterization was carried out by X-Ray Diffraction to identify the phases formed after MA process, the crystals size was determined by Rietveld method using the MAUD software [6]. This results were obtained with a value of $\mathrm{chi}^{2}: 1.33$ and $\mathrm{Rwp}=8.28$ respectively. Finally, analysis of Scanning electron microscopy (SEM) and Energy dispersive spectroscopy (EDS) were used to determine the morphology and chemical composition of the particles formed.

Figure 1 shows the X-Ray results of the alloy. It is possible to observe the presence of different peaks, which correspond to the $\mathrm{Cu}$ and Mo elements. By other hand the Rietveld analysis showed a crystal size of 13 and $24 \mathrm{~nm}$ and a microdeformation of $38.5 \times 10^{-4}$ and $3.6 \times 10^{-6}$ R.M.S., for the Co and Mo respectively.

Figure 2a shows the morphology of the particles analyzed by SEM. It can be observed a different morphology of the particles, the average size is ranking between 5-30 nm. The chemical composition of the particles can be observed in figure $2 \mathrm{~b}$ where $\mathrm{Cu}$ and Mo peaks are observed. It is possible to observe that ther is not a presence a other peak, which can indicate contamination from the steel balls used during the milling, the quantification of the elements indicated that the particles are composed of $94.56 \% \mathrm{wt}$ and $5.46 \% \mathrm{wt}$ of $\mathrm{Cu}$ and Mo respectively.

References:

[1] Davis, J. R. Copper and copper alloys. ASM international. (Ed.). (2001).

[2] Zhao, Q., et al Powder Technology, 321 (2017), p. 326-335.

[3] Ghorbani, A., Sheibani, S. Journal of Alloys and Compounds, 732, (2018), p. 818-827.

[4] Chen, X., et al. High Pressure. (2017), p. 1-12.

[5] Hamlati, Z., et al. Journal of Nano Research, 47, (2007), p. 79-88).

[6] L. Lutterotti, S. Matthies, and H.-R. Wenk. MAUD: a friendly Java program for material analysis using diffraction. IUCr: Newsletter of the CPD, 21:14-15, 1999. 


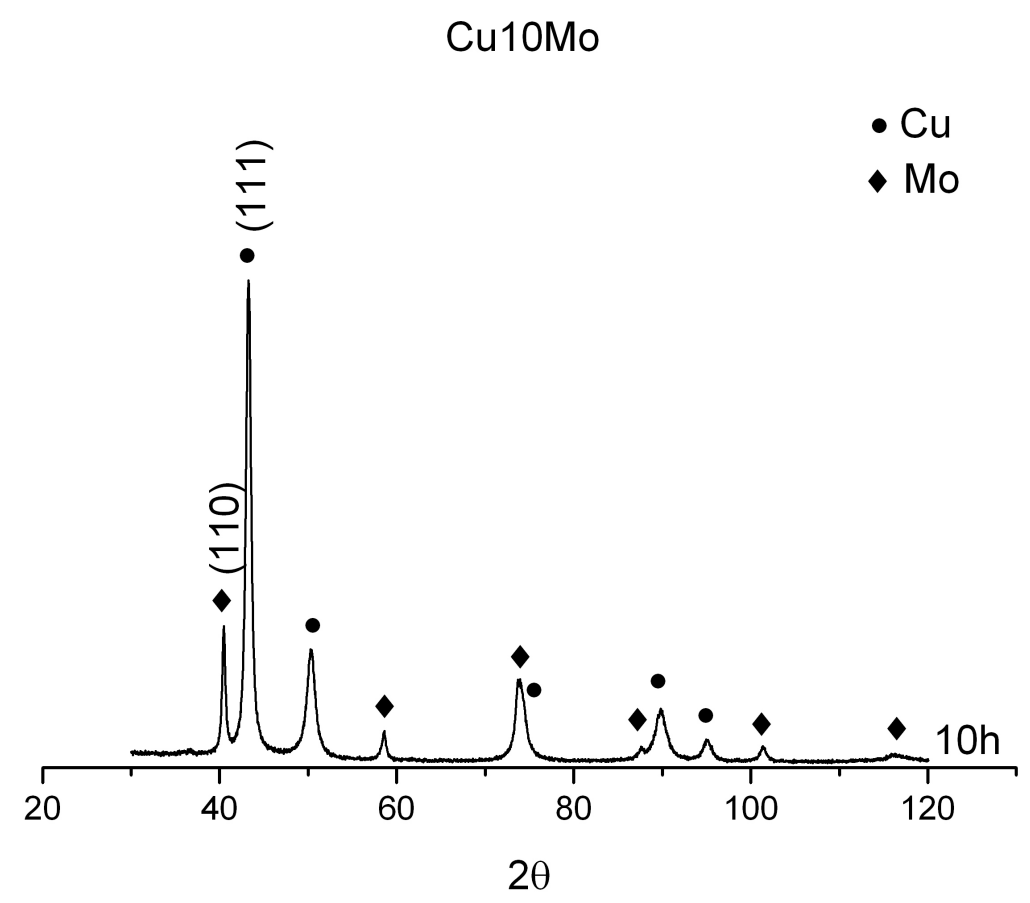

Figure 1. XRD analysis of Cu10Mo alloy milled for $10 \mathrm{~h}$

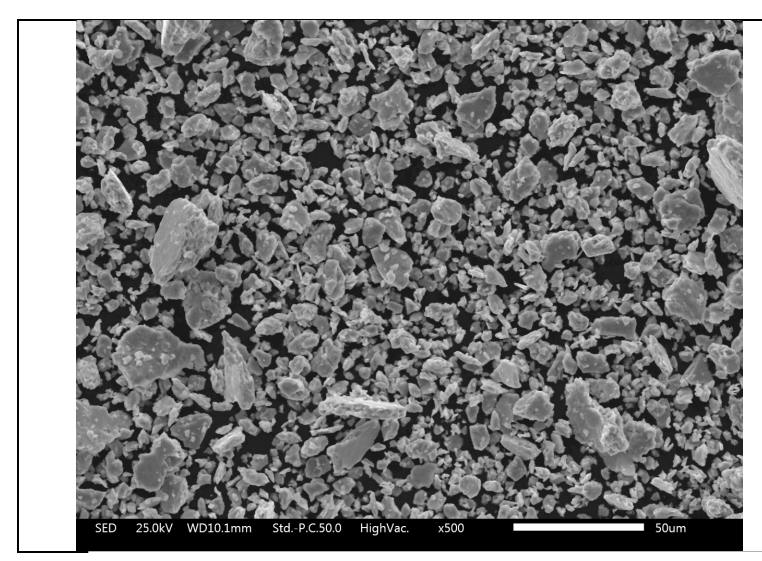

(a)

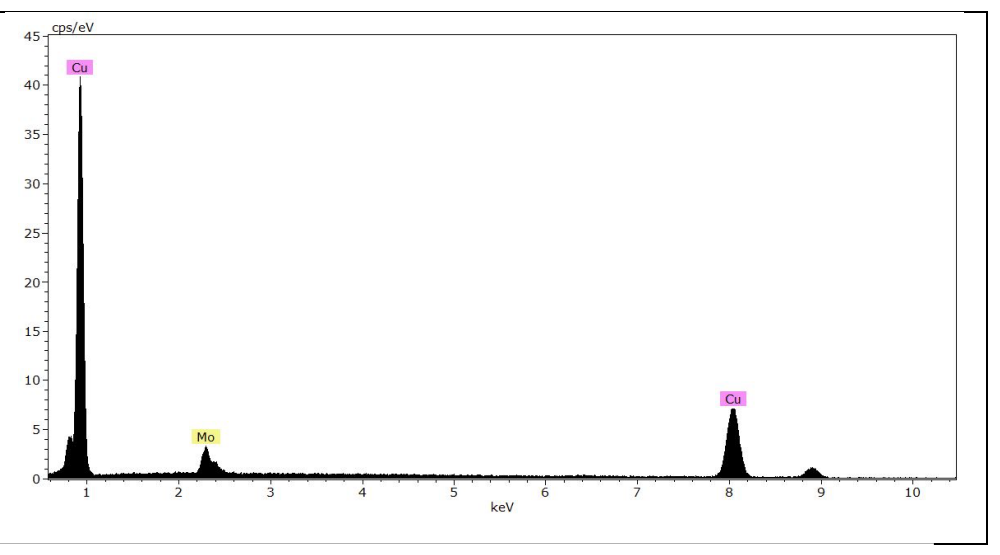

(b)

Figure 2. Cu10Mo alloy milled for $10 \mathrm{~h}$ a) SEM image and b) EDS analysis 